\title{
Abordagem sociolinguística em coleções aprovadas pelo Plano Nacional do Livro Didático
}

\author{
Sociolinguistic approach in collections approved \\ by Plano Nacional do Livro Didático
}

\section{Enfoque sociolinguístico en colecciones aprobadas por el Plan Nacional del Libro Didáctico}

\author{
Álida Laryssa Espozetti de Assis ${ }^{1}$ \\ Taciane Marcelle Marques ${ }^{2}$ \\ Wéllem Aparecida de Freitas Semczuk ${ }^{3}$
}

\begin{abstract}
RESUMO: A heterogeneidade linguística é uma realidade que vem sendo amplamente estudada pela Sociolinguística. O conhecimento de sua importância conduziu alguns dos pesquisadores da área a repensar o ensino da língua portuguesa no Brasil, pois há muitos que consideram apenas a norma culta, desprestigiando outras variedades. Esse novo pensamento é relevante para a pedagogia da variação linguística, no entanto, ainda é possível encontrar tanto uma defasagem no ensino quanto a existência do preconceito linguístico, por isso torna-se imprescindível a abordagem da variação em sala de aula, como sugerem os documentos oficiais para o ensino de língua portuguesa. Diante disso, este trabalho objetiva identificar, nas obras aprovadas pelo Programa Nacional do Livro Didático, de 2015, se há a menção da variação linguística e como ocorre esta abordagem nas atividades que envolvem o ensino de língua materna. Para tanto, selecionaram-se duas coleções de livros didáticos, uma destinada aos anos finais do ensino fundamental - do $6^{\circ}$ ao $9^{\circ}$ ano - e a outra ao ensino médio - da $1^{\text {a }}$ a $3^{\mathrm{a}}$ série. Como objetivos específicos, delimitam-se: (i) verificar se o PNLD apresenta a orientação da abordagem da variação linguística; (ii) identificar a abordagem da variação linguística nos objetivos do ensino de língua portuguesa presentes em cada ciclo escolar dos manuais didáticos analisados, (iii)

\footnotetext{
${ }^{1}$ Doutoranda do Programa de Pós-graduação em Estudos da Linguagem pela Universidade Estadual de Londrina. Contato: espozetti@gmail.com

2 Doutoranda do Programa de Pós-Graduação em Estudos da Linguagem pela Universidade Estadual de Londrina. Contato: taciane.marcelle@gmail.com

3 Doutoranda do Programa de Pós-graduação em Estudos da Linguagem pela Universidade Estadual de Londrina. Atualmente, professora do curso de graduação em Letras da Universidade Pitágoras Unopar, modalidade a distância. Contato: wellemsemczuk@gmail.com
} 
analisar as coleções tendo por base os estudos de Lima (2014). A análise demonstrou que já há livros que abordam de maneira adequada a temática da variação, porém ainda há um longo percurso a percorrer, pois a coleção destinada ao ensino médio ainda apresenta lacunas quanto a este assunto.

Palavras-chave: Sociolinguística. Pedagogia da variação. Manuais didáticos.

ABSTRACT: The linguistic heterogeneity is a reality that has been widely studied by Sociolinguistics. The knowledge of its importance led some of the researchers in the area to rethink the teaching of the Portuguese language in Brazil, because them consider only the cultured norm, discrediting other varieties. This new thinking is relevant to the pedagogy of linguistic variation, however, it is still possible to find both a lag in teaching and the existence of linguistic prejudice, so it is essential to approach the variation in the classroom, as suggested by the documents for teaching Portuguese. Therefore, this paper aims to identify, in the works approved by the National Textbook Program, of 2015, if there is a mention of linguistic variation and how this approach occurs in the activities that involve the teaching of mother tongue. For this, two collections of textbooks were selected, one for the final years of elementary school - grades 6 to 9 and the other for secondary education - from 1st to 3rd grade. Specific objectives are: (i) to verify if the National Textbook Program presents the orientation of the linguistic variation approach; (ii) to identify the linguistic variation approach in the objectives of Portuguese language teaching present in each school year of the textbooks analyzed; (iii) to analyze the collections based on the Lima (2014) studies. The analysis showed that there are already books that adequately address the theme of variation, but there is still a long way to go, because the collection destined for high school still presents gaps in this subject.

Keywords: Sociolinguistics. Pedagogy of linguistic variation. Textbooks.

RESUMEN: La heterogeneidad linguística es una realidad que viene siendo ampliamente estudiada por la Sociolinguística. El conocimiento de su importancia ha llevado a algunos investigadores a repensar la enseñanza del portugués en Brasil, porque hay muchos que consideran sólo el estándar de la norma, desprestigiando a otras variedades. Este nuevo pensamiento es relevante para la pedagogía de la variación linguística, sin embargo, todavía es posible encontrar tanto un desfase en la enseñanza como la existencia del prejuicio linguístico, por eso es esencial el enfoque de la variación en el aula, como se sugiere en los documentos oficiales para la enseñanza del idioma portugués. En este sentido, este trabajo objetiva identificar, en las obras aprobadas por el Programa Nacional del Libro Didáctico, de 2015 , si hay la mención de la variación lingüística y cómo ocurre este abordaje en las actividades que involucran la enseñanza de lengua materna. Para ello, se seleccionó dos colecciones de libros didácticos, una destinada a los años finales de la enseñanza fundamental - del 6 al $9^{\circ}$ año - y la otra a la enseñanza media - de la $1^{a}$ a $3^{a}$ serie. Como objetivos específicos, se delimitan: (i) comprobar si el Pnld presenta la orientación del abordaje de la variación lingüística; (II) identificar el enfoque de la variación lingüística en los objetivos de la ensenãnza de lengua portuguesa en cada ciclo escolar de los coleciones de libros didácticos analizados, (iii) analizar las colecciones basándose en los estudios de Lima (2014). El análisis demostró que ya hay libros que abordan de manera adecuada la temática de la variación, pero todavía hay un largo camino por recorrer, 
porque la colección destinada a la enseñanza media aún presenta deficiencias en lo referente a esta cuestión.

Palabras clave: Sociolingüística. Pedagogía de la variación. Manuales didácticos.

\section{CONSIDERAÇÕES INICIAIS}

As línguas apresentam um dinamismo inerente; encontram-se variações resultantes de fatores internos ou externos à língua, afinal sua utilização ocorre em meio à comunidade de falas, que estão inseridas na sociedade.

Dessa maneira, é imprescindível a abordagem das variedades linguísticas em sala de aula, conforme apontam os Parâmetros Curriculares Nacionais (1998) o aluno deve saber reconhecer e se adequar tanto na modalidade oral quanto escrita "nas inúmeras situações sociais do exercício da cidadania que se colocam fora dos muros da escola." (BRASIL, 1998, p. 25).

Diante disso, este trabalho objetiva identificar nas obras aprovadas pelo Programa Nacional do Livro Didático, doravante denominado de PNLD, de 2015, se há a menção da variação linguística e de que maneira ocorre esta abordagem nas atividades que envolvem o ensino de língua materna. Para tanto, foram selecionadas duas coleções de livros didáticos, uma destinada aos anos finais do ensino fundamental - do $6^{\circ}$ ao $9^{\circ}$ ano - e outra ao ensino médio - da $1^{\text {a a }} 3^{\mathrm{a}}$ série. Como objetivos específicos, delimitam-se: (i) verificar se o PNLD apresenta a orientação da abordagem da variação linguística; (ii) identificar a abordagem da variação linguística nos objetivos do ensino de língua portuguesa presentes em cada ciclo escolar dos manuais didáticos analisados, (iii) analisar as coleções tendo por base os estudos de Lima (2014).

Por fim, cabe ressaltar, que a escolha das coleções referentes a estes ciclos deu-se para que fosse possível contrastar os resultados encontrados, nesta pesquisa, com os expostos por Lima (2014).

\section{REFERENCIAL TEÓRICO}


Nesta seção, há algumas discussões, de pesquisadores renomados, relacionadas à língua, ao fenômeno da variação e à sua abordagem em âmbito escolar.

\subsection{Sociolinguística Educacional}

A Sociolinguística Educacional é uma das ramificações da Sociolinguística, bem como a Sociolinguística Interacional e a Sociolinguística Variacionista. Com relação à Sociolinguística Educacional, é válido destacar o aumento no número de estudos sobre a aplicação da Sociolinguística ao ensino, principalmente relacionada aos temas de analfabetismo e a precariedade da instrução escolar sobre o multilinguísmo (BORTONI-RICARDO, 2005); o preconceito linguístico (BAGNO, 2006); o prestígio do português culto predominante nas escolas (BAGNO, 2007; BORTONI-RICARDO, 2005; CASTILHO, 2002; FARACO, 2008); a conscientização dos alunos sobre os diferentes modos de falar o Português (CYRANKA, 2015; FARACO, 2002, 2008). Dessa forma, a Sociolinguística Educacional objetiva um amplo reconhecimento da heterogeneidade linguística, começando por apresentá-la aos alunos, ao abordar além das variedades prestigiadas, as estigmatizadas esclarecendo os motivos do prestígio associado à norma culta e sua importância para a sociedade.

De acordo com Bortoni-Ricardo (2005, p. 14);

O cidadão erudito aprecia a língua culta, que por sinal é o seu meio natural de comunicação, mas o trabalhador braçal, a empregada doméstica, os milhões de iletrados também o fazem. Demonstram igualmente um sentimento positivo em relação à "boa linguagem", à linguagem daqueles que têm estudo. [...] $O$ prestígio associado ao português-padrão é sem dúvida um valor cultural muito arraigado, herança colonial consolidada nos nossos cinco séculos de existência como nação. Podemos e devemos questioná-lo, desmistificá-lo e demonstrar sua relatividade e seus efeitos perversos na perpetuação das desigualdades sociais, mas negá-lo, não há como. 
Compreende-se, portanto, que as instituições escolares devem considerar tanto o prestígio social do português-padrão como as diferenças sociolinguísticas. Os professores, por sua vez, devem demonstrar aos alunos a existência das variedades linguísticas e que eles podem utilizá-las de acordo com a situação de comunicação em que se inserem, levando em consideração o interlocutor. Assim, o aluno também deverá ter contato e compreender o uso da norma culta, pois em determinadas situações ela é necessária. Dessa forma, a escola auxiliará na mudança do preconceito linguístico em relação às variedades estigmatizadas. O professor deve frisar que a língua é um conjunto de variedades e, principalmente, deve considerar a variedade dos alunos, partindo desta para fazê-los conhecerem a norma culta e a norma-padrão.

Convém destacar neste trabalho ainda os conceitos de norma culta e norma-padrão, sobretudo porque estão presentes e são valorizados no ensino de Língua Portuguesa. Para os estudos linguísticos, de acordo com Faraco (2008), "norma" é um conjunto de fatos linguísticos utilizados por um grupo, dessa forma, a norma também inclui fenômenos de variação linguística. A norma também se define a partir de valores socioculturais vinculados aos usos linguísticos. $\mathrm{O}$ autor afirma que o mesmo falante domina várias normas da mesma língua.

A mais prestigiada é a denominada norma culta, a qual consiste na variedade utilizada pelos falantes "cultos", ou seja, "falantes urbanos com escolaridade superior completa, em situações monitoradas" (FARACO, 2008, p. 47). Trata-se de um falante que usa a variedade característica dos extremos dos contínuos propostos por Bortoni-Ricardo (2005) contínuo rural-urbano, contínuo oralidade letramento e contínuo de monitoração estilística. Convém ressaltar que a norma culta é apenas uma das variedades que constitui a língua, sendo que umas sofrem mais estigma que outras. A norma culta, dentre todas, é a que mais se aproxima da norma-padrão.

Segundo Faraco (2008), a norma padronizadora é um fenômeno relativamente abstrato, pois busca por uma uniformização da língua. Os dicionários e as gramáticas se ocupam de divulgar essa norma, a fim de homogeneizar a 
língua. O autor aponta que o objetivo da norma-padrão no Brasil foi combater as variedades populares;

Se no século XVIII, com o Diretório dos índios, se buscou implantar uma política que visava calar as línguas indígenas, em especial a chamada língua geral, no século XIX, a intenção era calar as variedades rurais e (progressivamente) rurbanas. Nesse afã, os formuladores e defensores da norma-padrão se opuseram com igual furor às características das variedades populares e às das variedades cultas falada aqui. $O$ excessivo artificialismo do padrão que estipularam impediu, porém, que ele se estabelecesse efetivamente entre nós (FARACO, 2008, p. 80).

A fim de concretizar essa proposta, o professor deve considerar a pedagogia da variação linguística. Faraco (2008), após discutir o conceito de normas e variedades, propõe aos professores que desenvolvam uma pedagogia da variação linguística, ou seja, que assumam a inexistência de "erros" no uso que os falantes fazem de sua própria língua. A partir disso, o professor deve desconstruir alguns pensamentos equivocados sobre a língua e sobre como deve ocorrer 0 trabalho com a linguagem nas escolas, principalmente, quando se tem em vista alunos falantes rurais/urbanos ${ }^{4}$. Bortoni-Ricardo (2005) propõe que se considere nesse tipo de caso a pedagogia culturalmente sensível ${ }^{5}$, haja vista que mesmo um aluno com esse perfil é capaz de desenvolver habilidades no uso da língua.

Segundo a autora, o objetivo da Pedagogia culturalmente sensível é "criar em sala de aula ambientes de aprendizagem onde se desenvolvam padrões de participação social, modos de falar e rotinas comunicativas presentes na cultura dos alunos." (BORTONI-RICARDO, 2005, p. 128). Para facilitar a transmissão de conhecimento é necessário, portanto, trabalhar com questões verdadeiras para os alunos, pois os processos cognitivos associados aos processos sociais que thes são familiares serão ativados.

\subsection{A abordagem sociolinguística nos documentos oficiais de ensino}

${ }^{4} \mathrm{O}$ termo rural/urbano ou rurbano, proposto por Bortoni-Ricardo (2004), visa classificar aquele falante posto no meio desse contínuo rural-urbano, pois tem conhecimento e contato com a norma culta, mas não é capaz de utilizá-la adequadamente quando a situação de comunicação assim exige.

${ }^{5}$ Termo cunhado por Erickson (1987). 
É possível verificar que a Sociolinguística, bem como o tratamento da variação linguística em sala de aula, já vem sendo apontada pelos documentos oficiais. Os Parâmetros Curriculares Nacionais do Ensino Fundamental Anos Finais menciona o uso da variação em sala de aula. Esse documento propõe o trabalho com a linguagem adequada à determinada situação;

[...] o que se almeja não é levar os alunos a falar certo, mas permitir-lhes a escolha da forma de fala a utilizar, considerando as características e condições do contexto de produção[...] saber coordenar satisfatoriamente o que fala ou escreve e como fazê-lo; saber que modo de expressão é pertinente em função de sua intenção enunciativa. Dado o contexto e os interlocutores a quem o texto se dirige. A questão não é de erro, mas de adequação às circunstâncias de uso, de utilização adequada da linguagem (BRASIL, 1998, p. 31).

Os Parâmetros Curriculares Nacionais: Ensino Médio: língua portuguesa também trata a linguagem como meio de interação. $O$ documento propõe alguns objetivos para nortear o ensino de forma que os alunos consigam "prosseguir os estudos e participar da vida social" (BRASIL, 2000, p. 6), dentre eles, observa-se a preocupação em incluir as diferentes manifestações de linguagens utilizadas por diferentes grupos sociais, bem como o respeito a essas variedades.

O Pnld estabelece critérios de avaliação por quais passam os livros didáticos a serem adquiridos pelo Governo para o uso no ensino público e ressalta a necessidade da abordagem da variação linguística nos manuais de apoio ao professor. No Pnld do Ensino Fundamental anos finais, um dos critérios observados é se a coleção está organizada de forma a garantir ao aluno desenvolvimento da linguagem oral e escrita. Com relação especificamente à variação linguística, a coleção deve garantir ainda;

2.3. O desenvolvimento de atitudes, competências e habilidades envolvidas na compreensão da variação linguística e no convívio democrático com a diversidade dialetal, de forma a evitar o preconceito e valorizar as diferentes possibilidades de expressão linguística;

2.4. O domínio das normas urbanas de prestígio, especialmente em sua modalidade escrita, mas também nas situações orais públicas em que seu uso é socialmente requerido (BRASIL, 2013, p. 16). 
Da mesma forma, o Pnld para o Ensino Médio ainda prevê que a coleção contemple uma abordagem pedagógica da variação, como se verifica em seus princípios e objetivos gerais para a disciplina de língua portuguesa;

\footnotetext{
No ensino da norma-padrão, por outro lado, torna-se necessário: • abordar os fatores socioculturais e políticos que entram em jogo no estabelecimento e difusão de ideais e padrões linguísticos; • considerar a língua padrão no contexto da variação linguística, sem estigmatizar as demais variedades (BRASIL, 2014, p. 13).
}

Esse guia busca por uma coleção de Ensino Médio que considere tanto a norma-padrão quanto as variedades linguísticas, além de capacitar o aluno para analisar e refletir sobre o uso linguístico, quando essa prática for necessária ao desenvolvimento da proficiência oral e escrita.

Observa-se, portanto, que os documentos que norteiam a elaboração dos livros didáticos já trazem considerações favoráveis e importantes sobre a heterogeneidade linguística e sua abordagem nas aulas de língua portuguesa.

\section{METODOLOGIA E CORPORA ANALISADO}

Essa pesquisa tem como foco o ensino de Língua Portuguesa. Salienta-se que a Língua Portuguesa é heterogênea e que a abordagem da variação linguística no ensino da língua é essencial para o desenvolvimento do indivíduo e para a diminuição do preconceito linguístico. É necessário um ensino que considere a realidade linguística do aluno para, em seguida, apresentar-Ihe diversas variedades, populares e culta, bem como a norma-padrão da língua, um dos objetivos da escola.

Ao entender que o ensino da Língua Portuguesa deva contemplar as variedades linguísticas, é preciso averiguar se os manuais didáticos, que auxiliam os professores em sala de aula, trazem esta abordagem.

Lima (2014) propõe a análise de dois manuais didáticos a fim de verificar se, em novas edições dessas obras, a abordagem da variação linguística vem ocorrendo nesses manuais. $O$ autor selecionou para análise duas edições das obras: 
Português: linguagens, $6^{\circ}$ ano (edição de 1998 e de 2009) e Português: volume único (edição de 2000 e 2011). Para avaliar essas obras, o autor trouxe quatro questionamentos:

1. A variação linguística é uma constante na obra ou aparece de forma pontual, isolada?

2. A terminologia utilizada pelo livro se adequa aos padrões científicos ao mesmo tempo que é acessível ao aluno?

3. Há utilização de gêneros textuais que sejam representativos das variantes linguísticas abordadas, em situações reais de uso?

4. Os fenômenos abordados estão coerentes com a realidade linguística do $\mathrm{PB}$ ?

Com relação à obra Português: linguagens, $6^{\circ}$ ano, o autor verificou que não houve alterações na edição de 2009 com relação à abordagem da variação linguística, visto que essa abordagem já existia na edição de 1998. Nas duas edições a heterogeneidade linguística é abordada em um capítulo intitulado "As variedades linguísticas", no entanto o autor não reportou a abordagem da variação em outras partes das obras. Segundo Lima (2014), os autores desse manual didático se basearam na teoria da sociolinguística para a realização do capítulo sobre variação e apresentaram definições de termos da área. No entanto, comenta que não é suficiente apenas torná-los conhecidos pelos alunos, é necessária uma abordagem a partir das variedades linguísticas. $O$ autor menciona também que esses manuais do $6^{\circ}$ ano não apresentaram gêneros textuais com variantes em situação real de uso. Na edição de 1998, havia maior variedade de gêneros, inclusive um texto representativo do português não padrão. Lima (2014) aponta que apenas no capítulo sobre variação o aluno é instigado à reflexão linguística.

A respeito das edições de Português: volume único, utilizado no Ensino Médio, Lima (2014) relata que houve mudanças, principalmente porque na edição de 2000 a heterogeneidade linguística não era abordada, mas na edição de 2011 há um capítulo para o assunto, intitulado "a língua e suas variedades". Segundo Lima 
(2014), no conteúdo do livro, de forma geral, a abordagem linguística é igual nas duas edições, pois apresentam exercícios de fixação gramatical, salvo o capítulo voltado ao conteúdo de variação. Na edição de 2011, no capítulo de variação linguística foram usados termos da teoria sociolinguística, mas Lima (2014) afirma que a linguagem utilizada poderia ser mais adequada. $O$ autor menciona também a discrepância na abordagem linguística existente entre o capítulo sobre variação e o restante da obra, que se utiliza apenas da teoria gramatical tradicional. De acordo com o autor, apenas a edição de 2011 utilizou gêneros textuais com variedades em situações reais de uso.

De maneira geral, verificou-se que a obra do Ensino Fundamental não apresentou modificações, exceto pelo tipo de gêneros textuais abordados, enquanto que, no manual do Ensino Médio, acrescentou-se um capítulo sobre a variação linguística na versão mais recente (2011).

O autor revela que as obras analisadas abordam a variação linguística apenas em um único capitulo, a respeito disso, comenta;

Isso é curioso porque temos a impressão nítida de que há uma pressão, por parte de órgãos oficiais, para se abordar a questão das variações linguísticas nos livros didáticos. No entanto, para fazer um trabalho ao longo do livro, é necessário reformular todo o conteúdo. Assim, elaborar um capítulo sobre o assunto "basta" para torná-lo aceito oficialmente, o que não deveria acontecer (LIMA, 2014, p. 127).

Com base nas questões elaboradas por Lima (2014), essa pesquisa se propõe a averiguar os corpora selecionados para a análise: (i) Coleção de livro didático do ensino fundamental anos finais - Jornadas.port, (ii) Coleção de livro didático do ensino médio - Português: língua e cultura. Diferentemente de Lima (2014), nesta pesquisa, optou-se por analisar apenas a edição aprovada pelo Pnld mais recente, além do mais, adotou-se essa análise para todos os livros das coleções, a fim de observar se a variação linguística é mais abordada em um ano do ciclo escolar do que em outro.

Buscou-se analisar os livros didáticos selecionados a fim de averiguar se as respostas encontradas convergem ou divergem das expostas por Lima (2014). 


\section{ANÁLISE E DISCUSSÃO DOS DADOS}

Neste tópico, analisaram-se, a partir das questões norteadoras da pesquisa de Lima (2014), duas coleções de livros didáticos: Jornadas.port, referente ao ensino fundamental anos finais e Português: língua e cultura referente ao ensino médio; ambas aprovadas pelo Plano Nacional do Livro Didático e adotadas pelo ensino público.

\section{Coleção ensino fundamental anos finais}

A coleção Jornadas. port é constituída de quatro unidades, sexto ao nono ano, sendo cada unidade composta de oito capítulos. Estes capítulos são divididos pelos seguintes tópicos: Leitura; Exploração do texto; Produção oral e escrita; Reflexão sobre a língua.

A respeito das questões norteadoras de Lima (2014), verificou-se nesta coleção:

I. A variação linguística é uma constante na obra ou aparece de forma pontual e isolada?

A variação linguística na coleção Jornadas.port é recorrente na obra, por estar presente em todas as unidades da coleção. Observa-se que o tema não é abordado somente em capítulos específicos de variação linguística, mas constantemente e nos mais diversos conteúdos: leitura; gêneros textuais; gramática; ortografia; como se verifica no exemplo a seguir;

Figura 1 - Substantivo e norma-padrão 


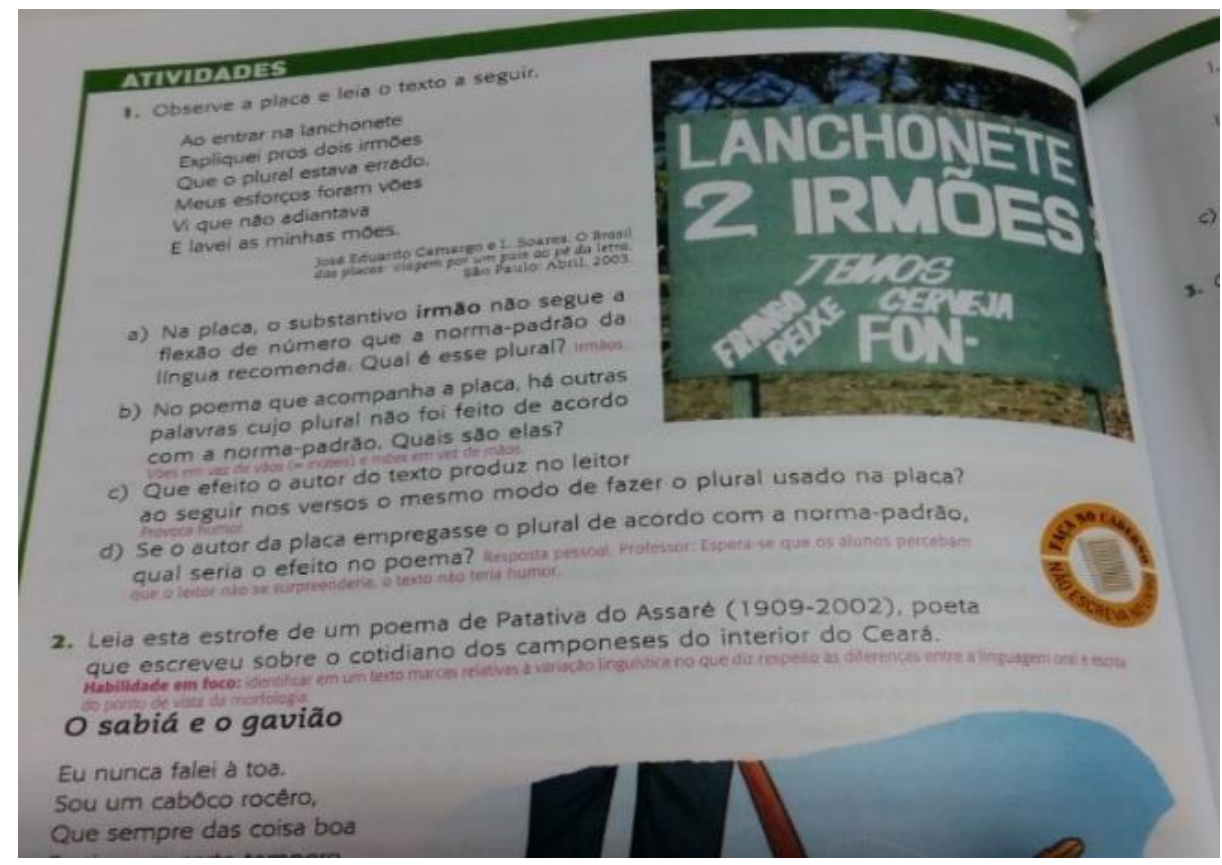

Esta atividade, presente no capítulo que tem por base o gênero textual carta, encontra-se na seção "Reflexão sobre a língua", que busca introduzir a classe gramatical substantivo. Para auxiliar o aluno a refletir sobre a flexão de número nesta classe gramatical, encontram-se textos pautados pela norma não padrão. Primeiramente, uma placa anunciando a "Lanchonete dois irmões" e, posteriormente, um texto literário relacionado ao desvio da norma-padrão encontrado na placa. A partir destes textos e das atividades conseguintes, caberá ao aluno compreender os contextos aos quais os textos pertencem e observar a intenção na escolha da linguagem utilizada. Para tanto, é imprescindível que se tenha, também, o conhecimento da norma-padrão, pois sem este conhecimento o aluno não conseguirá apreender a intenção do texto.

A atividade é enriquecedora ao não solicitar que o aluno faça uma simples correção destes textos para a norma-padrão, mas sim que assimile as variedades presentes na língua e consiga reconhecê-las em cada situação de uso.

II. A terminologia utilizada se adequa aos padrões científicos ao mesmo tempo que é acessível ao aluno? 
As unidades da coleção introduzem, de forma progressiva, as terminologias referentes à Sociolinguística. Estas terminologias respeitam o padrão científico, ao mesmo tempo em que são acessíveis aos alunos por serem explicadas de maneira didática e adequada a faixa etária. Observa-se o exemplo a seguir;

Figura 2 - Terminologias

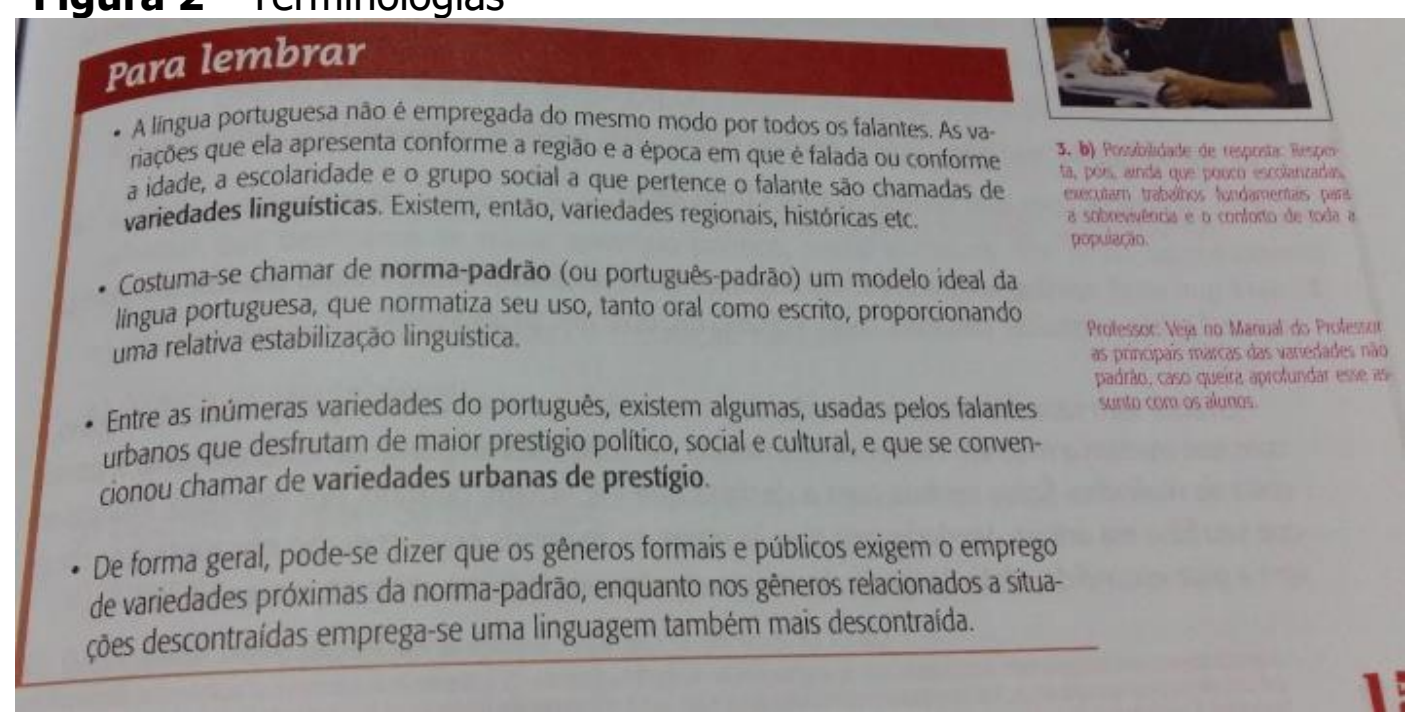

$\mathrm{Na}$ unidade referente ao sexto ano, atenta-se para a explanação das terminologias fala e escrita, norma-padrão e não padrão e variedades linguísticas, já na unidade referente ao sétimo ano (Figura 2), os conceitos de variedades regionais, variedades históricas, variedades urbanas de prestígio, variação socioculturais, variação de registro e formalidade e informalidade são acrescidos na coleção. Além disso, a formulação das atividades que compõem as unidades utiliza coerentemente as terminologias pertencentes à abordagem sociolinguística.

III. Há a utilização de gêneros textuais que sejam representativos das variantes linguísticas abordadas, em situações reais de uso?

Todos os capítulos da coleção Jornadas. port possuem um gênero textual principal em que são baseadas as outras atividades do capítulo. Há, portanto, diversidade de gêneros textuais, e, há destaque para a linguagem utilizada nestes determinados gêneros, conforme se verifica na figura;

Figura 3 - Diário Virtual 


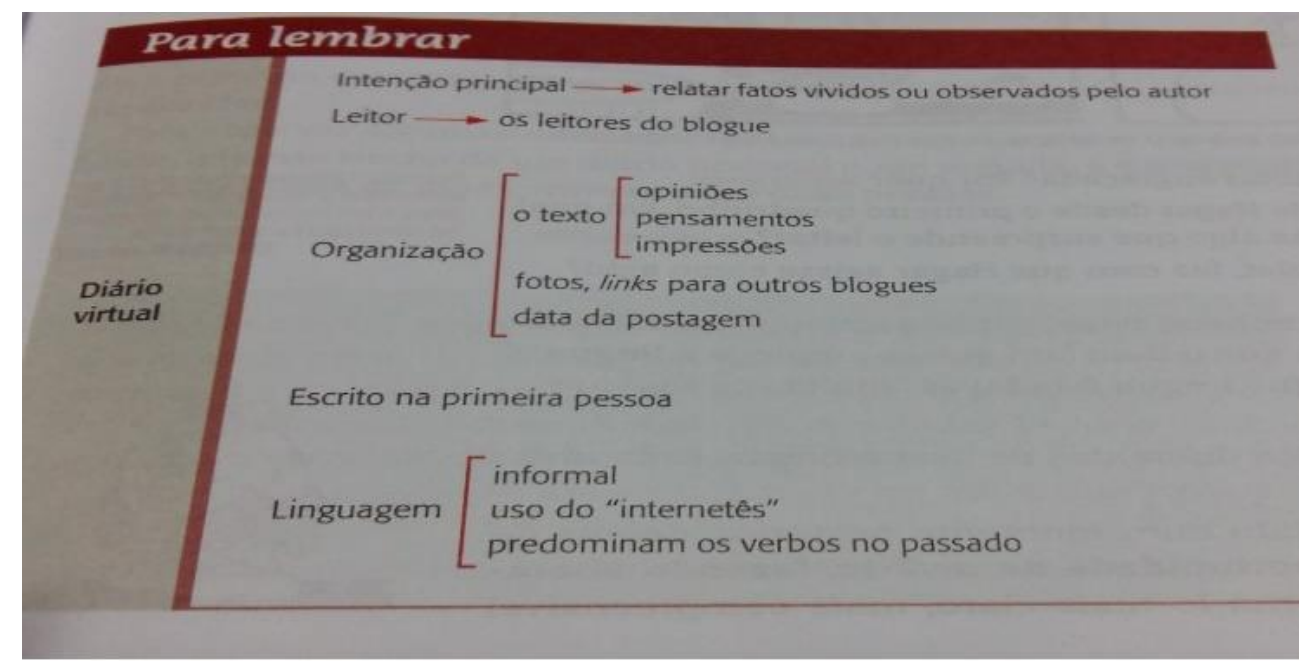

Nota-se a abordagem da linguagem inserida em um gênero textual. 0 gênero em questão, diário virtual, propicia ao aluno a reflexão sobre a utilização da linguagem informal, além da variação sociocultural, no caso mais específico, o fenômeno da gíria, ou do internetês, ocorrência relevante principalmente para a faixa etária que a coleção busca atingir. Estes aspectos representam situações reais de uso da linguagem do dia a dia.

\section{Os fenômenos abordados estão coerentes com a realidade linguística do PB?}

Há a presença de diversos fenômenos coerentes com a realidade linguística do português brasileiro no decorrer da obra. Entre estes fenômenos, destaca-se o que está ilustrado na figura;

Figura 4 - Tu e você 


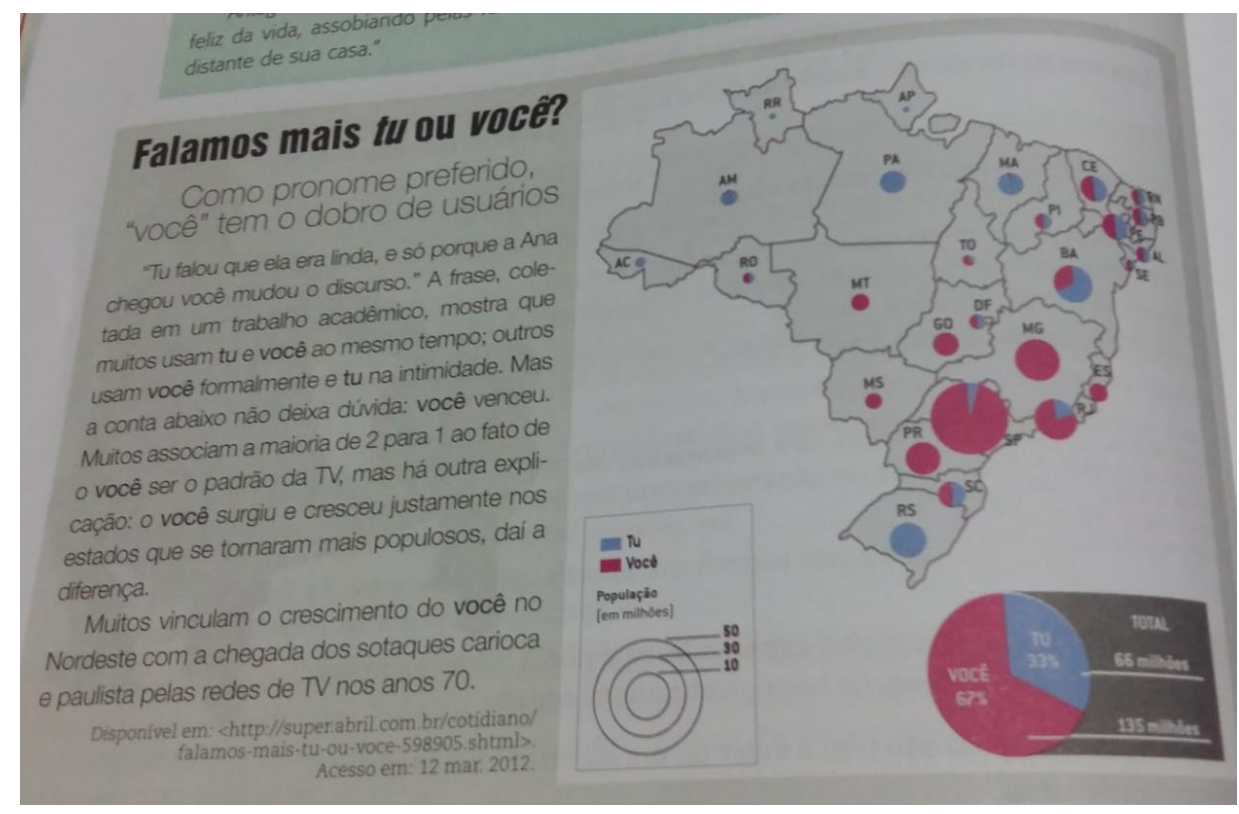

De acordo com Cegalla (2008, p. 132) o pronome tu é pessoal e refere-se à segunda pessoa do discurso, diferentemente do pronome você, classificado pelo autor, e por diversos gramáticos, como pronome de tratamento. Porém, segundo Castilho (2010, p. 479) "na segunda pessoa do singular, tu tem sido substituído por você, forma que surgiu por alterações fonológicas da expressão de tratamento Vossa Mercê, sintagma nominal que deu origem a você>ocê>cê." Os falantes da língua portuguesa no Brasil utilizam o pronome você em detrimento do pronome tu em determinadas regiões. A obra aborda este uso dos pronomes no Brasil, realçando qual pronome é predominante em cada região, e qual é mais empregado no país.

Sendo assim, o aluno tem contato com acontecimentos da língua em uso, e não somente com o que é pautado pela norma-padrão da língua e as atividades corroboram com o exposto por Bortoni-Ricardo (2005, p. 26), "a aprendizagem da norma culta deve significar uma ampliação da competência linguística e comunicativa do aluno, que deverá aprender a empregar uma variedade ou outra, de acordo com as circunstâncias da situação de fala". Dessa maneira, o ensino da gramática servirá para que o aluno consiga refletir sobre a língua em uso, sua estrutura e sua multiplicidade. 


\section{Coleção ensino médio}

A coleção Português: língua e cultura é composta por três volumes com quinze capítulos cada, sendo dividido em: Gêneros textuais, literatura, enciclopédia da linguagem, almanaque gramatical e apêndice - nos três volumes há o trabalho com pontuação, acentuação, crase e hífen. As questões propostas por Lima (2014) também nortearam a análise dessa coleção, como se verifica a seguir.

\section{A variação linguística é uma constante na obra ou aparece de forma pontual, isolada?}

A abordagem da variação linguística aparece bem pouco na coleção, apesar de constar nas orientações finais, destinada ao professor, que a obra trabalha com o ensino de língua em seu meio social e de acordo com o seu uso. Encontra-se de maneira mais pontual no livro do $2^{\circ}$ ano, em que o capítulo dez é destinado à variação, mas só há, nos três volumes, este capítulo que fala de variação, conforme mostra a figura que segue;

Figura 5 - Variação linguística

Sapútulo

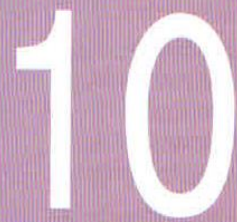

ENCICLOPÉDIA DA LINGUAGEM

\section{A LINGGUAÉ UM CONJUNTO DE VARIEDADES}

Não é dificil observar como a lingua portuguesa é falada de modos diferentes pelo Brasil afora. Também não é dificil observar como a língua varia conforme o estamento social dos falantes e como nós mesmos variamos continuamente nosso modo de falar:

conforme a situação em que estamos (formal ou informal);

conforme quem sejam nossos interlocutores (mais jovens ou mais velhos; conhecidos ou desconhecidos);

e conforme, ainda, o papel social que estamos exercendo naquele momento (aluno ou professor; chefe ou colega de trabalho).

Esses fatos, facilmente percebidos, apontam para uma característica de todas as linguas: nenhuma delas é uniforme, homogênea; todas conhecem variação na pronúncia, no vocabulário e na estruturação gramatical; todas se materializam como um conjunto de variedades geográficas, sociais e contextuais.

O autor mostra neste capítulo o conceito de língua heterogênea, ou seja, composta por um conjunto de variedades que podem ser, com base na classificação trazida pelo livro, por fatores geográficos, sociais e contextuais. Com relação à variação geografia expõe que este tipo de variação pode ser de ordem sintática, 
lexical e nas formas de tratamento do interlocutor - exemplifica estes itens comparando o português do Brasil e de Portugal. Dado interessante é que o autor pontua ainda a ideia de que não há uma variedade "melhor, mais bonita, mais certa do que a outra", mas sim que todas são organizadas e atendem às necessidades dos grupos que as usam.

Ao mencionar a variação social pontua aspectos que evidenciam a diferença entre a fala dos idosos e dos adolescentes, das pessoas que moram no campo e na cidade, das mulheres e dos homens e das pessoas com maior escolaridade em relação às pessoas de menor escolaridade. Já a variação contextual, denominada assim pelo autor, é entendida como a variação relacionada à situação comunicativa, pois não se fala sempre do mesmo jeito. Esta variedade é classificada por Camacho (1998) enquanto variação estilística e por Castilho (2010) como variação individual.

Vale ressaltar que nos demais livros e capítulos o assunto da variação linguística não é explorado, nem mesmo quando trabalhado os gêneros textuais, que são a base de todos os capítulos, em que a depender do gênero a linguagem tende a mudar, o que pode ser desconhecido pelo aluno, pois a escola tende a focar, principalmente, o ensino da norma-padrão.

\section{A terminologia utilizada se adequa aos padrões científicos ao mesmo tempo que é acessivel ao aluno?}

As terminologias, que se referem aos aspectos sociolinguísticos, quase não aparecem na obra, pois, como mencionado, há somente um capítulo em que aborda esta temática e este dedicou-se mais em esclarecer as diferenças entre os tipos de variação. Verifica-se, porém, a presença dos termos língua-padrão e coloquial. O termo língua-padrão, utilizado nessa coleção, assemelha-se ao conceito de norma culta, proposto por Faraco (2008). Principalmente porque a coleção utiliza os termos coloquial e língua-padrão como fazendo parte de variedades, como temos o exemplo na figura a seguir; 
Figura 6 - Conceito de língua-padrão

\section{LINGUA-PADRÃO}

Duas dificuldades nos acompanham quanto à língua-padrão. A primeira: a língua-padrão escrita é mais conservadora que a língua falada (padrão ou coloquial). A segunda: a linguapadrão é um peixe ensaboado.

Nesta figura verifica-se que o autor pretendia explicar que há diferenças entre a língua escrita e a língua falada, sendo a escrita, de acordo com a figura, mais conservadora. Porém, ao tentar explicar esta diferença acaba não trazendo a diferenciação entre os termos, tão pouco exemplos que poderiam elucidar a explicação, confundindo o aluno, principalmente, ao dizer que "a língua-padrão é um peixe ensaboado", sem explicar tal afirmação.

Há trechos que demonstram a preocupação em mostrar ao aluno que a padronização não pode ser entendida com o intuito de "aniquilar" a diversidade, mas, conforme já afirmado na figura anterior, como uma variedade em meio as outras.

Fora percebido que há denominações diferentes para os termos que se referem à norma-padrão/variedade-padrão e norma culta, porém o autor não apresenta na coleção a distinção dos termos, tanto que não há a definição de norma culta em nenhum dos livros. Há tópicos, em todas as unidades, sobre línguapadrão, demonstrando sua importância e necessidade, mas não há para os outros termos, tão importantes quanto, como, língua culta, coloquial, diversidade linguística, adequação da linguagem etc.. Vê-se também que foi trazido pelo livro a questão da variedade-padrão se fazer presente nos textos escritos, mas não foi comentado o motivo de não ser comum na língua falada. Sentiu-se falta de mais informações, totalmente relevantes ao aluno, para se compreender as variedades do português brasileiro.

Verifica-se, ao longo da coleção, que as atividades, que se referem à língua-padrão, tendem a menosprezar a língua falada, desprestigiá-la, pois recorrem a frases comuns na língua falada pedindo que estas sejam transcritas para a língua-padrão. Fica evidente que não há um trabalho efetivo a respeito da 
língua falada, tão pouco é mencionado pelos autores da coleção sua importância e variedade presente na língua. Mais uma vez pretende-se que o aluno saiba encontrar "erros" em frases descontextualizas, por vezes, comuns da fala, que são escritas com o objetivo de corrigi-las, pois não estão "adequadas".

III. Há a utilização de gêneros textuais que sejam representativos das variantes linguísticas abordadas, em situações reais de uso?

Há a utilização de gêneros textuais, em todas as coleções, mas são explorados apenas enquanto sua forma e interpretação. Não há menção ou mesmo uso dos gêneros em situações reais, tão pouco relacionando-se com as variantes linguísticas, o que temos é a apresentação do texto - gênero específico da ordem do narrar ou argumentar - e questões que, na maioria das vezes, são apresentadas de maneira superficial, conforme figura;

Figura 7 - Preconceito linguístico

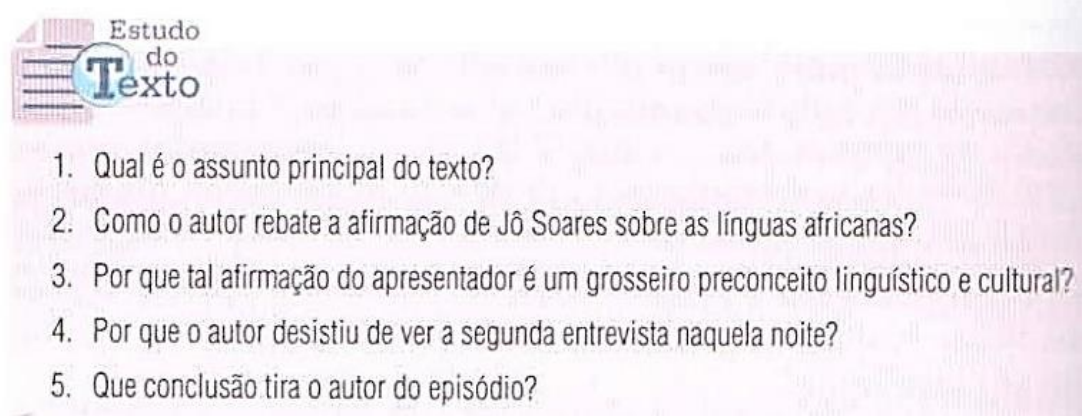

As perguntas se referem ao texto "Bobagens" de Sírio Possenti, dado importante para esta pesquisa é que a questão número três apresenta o termo preconceito linguístico e cultural, porém não há menção no livro de seus significados ou mesmo de exemplos que possam explicá-los. Outro ponto relevante e recorrente é que a particularidade da linguagem empregada em cada gênero não é mencionada. Não se tem a orientação, principalmente para o aluno, do tipo de linguagem a ser utilizada no gênero estudado, tão pouco o material traz a 
informação de que a depender do gênero textual a linguagem é alterada em decorrência de seu estilo. 
IV. Os fenômenos abordados estão coerentes com a realidade linguística do PB?

Os fenômenos abordados estão coerentes com o ensino que tem por base apenas a gramática normativa, pois há em toda a coleção questões gramaticais que só possuem frases, explicações simplificadas e correções de formas coloquiais, corriqueiras da fala. Nem mesmo o trabalho com os gêneros textuais se deu de forma efetiva, porque os autores da coleção utilizam o texto enquanto pretexto para se trabalhar aspectos gramaticais descontextualizados e interpretações que não levam o aluno à reflexão, conforme o exemplo que segue, em que o verbo haver precisa ser flexionado, adequadamente, de acordo com a frase, assim o aluno precisa preencher a lacuna da maneira "correta".

Figura 8 - Exercícios sobre o verbo ter e haver

1. Ontem, durante a discussão, (HAVER) várias sugestões, mas não (HAVER) nenhuma decisão.

2. Quando eu cheguei perto da praia, vi que (HAVER) muitos banhistas, mas não (HAVER) nenhum guarda-vidas.

3. Como no próximo campeonato (HAVER) muitos jogos no mesmo dia, fica a dúvida se (HAVER) torcedores em todos os estádios.

Fica perceptível, ao longo da análise, que questões como esta são recorrentes e que o objetivo da obra é levar o aluno, ao final de cada ciclo, a saber as regras gramaticais. Não houve a preocupação de contextualizar e trazer informações e usos do português brasileiro não-padrão.

\section{CONSIDERAÇÕES FINAIS}

Este trabalho objetivou verificar a abordagem da variação linguística nos livros didáticos destinados ao ensino fundamental anos finais e ao ensino médio, aprovados pelo Plano Nacional do Livro Didático. Considerou-se, como norte deste estudo, a pesquisa realizada por Lima (2014). A partir da análise constatou-se que o livro do ensino fundamental apresenta uma perspectiva Sociolinguística, conforme as orientações dos documentos oficiais - Parâmetros curriculares nacionais e Plano nacional do livro didático. O estudo de Lima (2014) pontua que os livros didáticos analisados em 1998 e 2009 abordavam, predominantemente, a gramática normativa, sendo a variação linguística presente em somente um capítulo. De 
acordo com o autor, só há a presença dos termos norma-padrão e norma culta, mas não há uma explicação ou conceituação desses termos, dificultando o entendimento dos alunos. Diferentemente dos resultados de Lima (2014), a coleção analisada nesta pesquisa trouxe elementos significativos para o trabalho com a diversidade da língua, por apresentar a variação linguística constantemente na obra nos mais variados conteúdos. Assim, utiliza as terminologias adequadas ao referencial sociolinguístico, tanto nas atividades, quanto em boxes que elucidam e tornam acessíveis os termos para o alunado. A coleção também aponta para a reflexão dos fenômenos do português brasileiro e para a diversidade da língua em uso.

Já a obra do ensino médio corrobora com a análise feita por Lima (2014) nas obras de 2000 e 2011, haja vista que os livros analisados pouco evidenciaram o trabalho com a língua em uso, focando, quase de modo exclusivo, o ensino de regras gramaticais descontextualizadas. Nas três obras só há um capítulo em que apresenta a variação linguística, igual os dados de Lima (2014), o que demonstra a despreocupação com o ensino de língua materna embasado na diversidade linguística. Nesta coleção ainda há terminologias que são muito repetidas - línguapadrão - mas pouco exploradas, não facilitando a compreensão do aluno e por vezes demonstravam ter mais de um sentido/significado.

Com base nos dados apresentados fica evidente que, apesar de ainda haver livros que não apresentam de maneira adequada a variação linguística, já há trabalhos sendo feitos nesta área, como o livro analisado "Jornadas. port" que a todo o momento buscou trazer questões relevantes sobre a diversidade da língua. Lima (2014) deixa em aberto a seguinte questão: "discutir a ausência de tratamento adequado a estes temas é importante, mas nos garantiria que os livros didáticos mudariam este tratamento?", apesar de não ter uma garantia do tratamento adequado destes temas é somente a partir de uma discussão na academia e na sociedade que poderá haver mudanças efetivas no ensino. Contudo, para isso não basta apenas à alteração no material didático, mas também uma 
formação Sociolinguística adequada ao professor, que irá trabalhar com este material.

\section{REFERÊNCIAS}

BAGNO, Marcos. Nada na língua é por acaso: por uma pedagogia da variação linguística. São Paulo: Parábola Editorial, 2007. 238 p.

BAGNO, Marcos. Preconceito linguístico: o que é, como se faz. São Paulo: Loyola, 2006. $186 \mathrm{p}$.

BORTONI-RICARDO, Stella Maris. Educação em língua materna: a sociolinguística em sala de aula. São Paulo: Parábola, 2004. 110 p.

BORTONI-RICARDO, Stella Maris. Nós cheguemu na escola e agora?:

Sociolinguística e educação. São Paulo: Parábola, 2005. 263 p.

BRASIL. Ministério da Educação. Secretaria de Educação Básica Guia de livros didáticos. PNLD 2015: língua portuguesa: ensino médio. Brasília, 2014. 104p.

BRASIL. Ministério da Educação. Secretaria de Educação Básica. Guia de livros didáticos. PNLD 2014: Língua Portuguesa: ensino fundamental: anos finais. Brasília, 2013. 120p.

BRASIL. Secretaria de Educação Fundamental. Parâmetros Curriculares Nacionais: terceiro e quarto ciclos do ensino fundamental: língua portuguesa. Brasília: MEC/SEF, 1998. 106p.

BRASIL. Secretaria de Educação. Parâmetros Curriculares Nacionais: ensino médio: língua portuguesa. Brasília: MEC/SEF, 2000. 71p.

CAMACHO, Roberto G. A variação linguística. In: SÃO PAULO (Estado), Secretaria da Educação. Coordenadoria de Estudos e Normas Pedagógicas. Subsídios à proposta curricular de língua portuguesa para o $1^{\circ}$ e $2^{\circ}$ graus. São Paulo: SE/CENP, 1988. p. 29-413. (Coletânea de Textos, v. I).

CASTILHO, Ataliba T. Nova gramática do português Brasileiro. São Paulo: Contexto, 2010.

CASTILHO, Ataliba T. Variação dialetal e ensino institucionalizado da língua portuguesa. In: BAGNO, Marcos (Org.). Linguística da norma. São Paulo: Loyola, 2002. p. 27-36.

CEGALLA, Domingos Paschoal. Nova minigramática da língua portuguesa. 3. ed. São Paulo: Companhia Editora Nacional, 2008. 
CYRANKA, Lucia F. Mendonça. A pedagogia da variação linguística é possível? In: ZILLES, Ana Maria Stahl; FARACO, Carlos Alberto (Org.). Pedagogia da variação linguística: língua, diversidade e ensino. São Paulo: Parábola, 2015. p. 31-51.

ERICKSON, Frederick. Transformation and school success: the politics and culture of educational achievement. Anthropology and Education Quarterly, Washington, v. 18, n. 4, p. 335-356, Dec. 1987.

FARACO, Carlos Alberto. Norma culta Brasileira: desatando alguns nós. São Paulo: Parábola Editorial, 2008. 205 p.

FARACO, Carlos Alberto. Norma-padrão brasileira: desembaraçando alguns nós. In: BAGNO, Marcos (Org.). Linguística da norma. São Paulo: Loyola, 2002. p. 37-61.

LIMA, R. J. Variação linguística e os livros didáticos de português. In: MARTINS, M. A. Ensino de português e sociolinguística. São Paulo: Contexto, 2014. p. 115-131. 